\title{
Preface
}

Chemistry is one of the central natural sciences that penetrates into and bridges various interdisciplinary fields. As the science that studies the interaction and transformations of the substances, chemistry aims to relate the properties of the matter to their structures, to develop innovative reaction and synthetic methods to create new matter in order to meet the increasing demands of the human beings.

The manufacture of ammonia by catalytic method at high temperature and pressure, known as one of the most important inventions of the 20th century, has revolutionized grain production and provided adequate food and clothing. Chemical synthesis has opened up a new era of innovative pharmaceutics which significantly protects the human health. Everywhere witnessed the contribution of chemistry from plastic products used in daily life, synthetic fibers, to structural materials used in various types of buildings and the high-performance materials in advanced technologies.

Chemistry has penetrated into every corner of the national economic development, improvement of the quality of human life and the national security. Chemistry will provide the material basis and technological support for further new energy, new material and information, medicine, resource and environments. Chemistry will keep on blazing new trails and play irreplaceable role in seeking green process, refinement and economy of the products, and recycling of the resources.

Since the reform and opening up, particularly over the last decades, Chinese chemistry has made great progress not only in the fundamental research, realizing a number of internationally well-known achievements, but also in the economical development, earning the intellectual property rights and industrialization of these patents. The National Science Library, Chinese Academy of Sciences (NSLC) has made a comparison of the recent ten years' statistical data including the number of the papers published in the SCI journals, citations, highly cited papers and hot papers with those of the other countries. It was concluded that among 19 senior subjects in natural sciences, Chinese chemistry developed very fast, and has been among the forefront in the world. China is now becoming a big country in chemical research.

Chinese chemical researchers should be more actively facing with the new challenges at the new period. First, they should take initiative and try to solve problems that hinder the economic development of the country while still pay attention to basic research that supports original innovations. Second, as one of the senior subjects, chemistry should continue its cross-domain integration and cooperation, with those of energy, life, information, material and environmental sciences and technologies. However, caution should be taken that this integration with other disciplines will encourage more profound chemical research rather than being merged. Third, Chinese chemists should pay more attention to protect their intellectual right and transfer the technology to industry. More efforts should be devoted to the environmental chemistry, green chemistry and chemistry related public security to let chemistry play more and more important role in the sustainable development and construction of a socialist harmonious society.

Science in China and Chinese Science Bulletin are sponsored by the Academic Divisions of Chinese Academy of Sciences. It is an important measure of building national soft power of science and technology to run a timely journal which reflects the most up-to-date scientific research in China. It is also an important contribution to submit the recent results to the journal. The publication of the special issue of Science in China Series B: Chemistry, in commemoration of the 60th birthday of China, embodied not only the great efforts of the editors-in-chief, associate editors-in-chief and editors but also the supports from the contributors. Chemical researchers are encouraged to submit continuously their excellent works to the two journals, making them increasingly prestigious in the academia. It is my sincere hope that Science in China Series B: Chemistry will make its due contribution to Chinese chemistry at the moment when the two journals Science in China and Progress in Natural Science are combined.

\section{Chunl: Bai}

Executive Vice President of Chinese Academy of Sciences Director of Chemistry Division of Chinese Academy of Sciences President of Chinese Chemical Society

doi: $10.1007 / \mathrm{s} 11426-009-0252-3$ 